\title{
The Important Role of Virtual Experiment in the Reform of Department of Mechanical and Electronic Engineering of Hankou University
}

\author{
Yan Deng ${ }^{1, a}$, Hongdong Zhang ${ }^{1, b}$ and Kangling Liu ${ }^{1, c}$ \\ ${ }^{1}$ Hankou University, Wuhan 430212, Hubei, China \\ adengyandy@126.com, b49919643@qq.com, ckangling17@qq.com
}

Keywords: Virtual experiment; Virtual reality; Mechanical and electronic engineering; Education reform

\begin{abstract}
Objective: To provide a method rapidly developing the Department of Mechanical and Electronic Engineering, we research on the education reform with virtual experiment.

Methods: Virtual experiments are introduced to many courses. Students are encouraged and trained to develop their own virtual experiments. The department cooperates with companies to establish the platform of training VR talents and developing 3D virtual experiments.

Results: Through those measures, teaching quality has been greatly improved, students' innovation ability has been enhanced significantly, and cooperation with enterprise has got remarkable achievements.

Conclusion: The results testified the mode of education reform with virtual experiment in the Department of Mechanical and Electronic Engineering is successful and applicable.
\end{abstract}

\section{Introduction}

Department of Mechanical and Electronic Engineering of Hankou University has a short histroy less than 5 years, and it was very weak at the beginning. In virtue of education reform, the department has made great development. In the paper, we research on the important role of virtual experiment in the reform and offer a new mode for the application of virtual experiment.

\section{Difficulties of the Department of Mechanical and Electronic Engineering}

Hankou College of Central China Normal University was founded in September 2000 and was one of the first four independent colleges established in China. In 2011, it was reorganized to Hankou University and became one of the first universities set up by independent colleges in China. Over the years, the university focused on literature, law, arts and media. In order to adapt to the development trend of Industry 4.0, Hankou University set up the Department of Mechanical and Electronic Engineering in 2012.

The newborn department had few students and were allocate very limited funds accordingly. Since the department was made up of many disciplines such as mechanical, electronic, control and so on, the courses require many kinds of experiments and a large number of equipment. It cost much to purchase and maintain those experimental equipment, especially some instruments were very expensive. Only a small part of the instruments were bought due to the limited funds. With the increase of students, experimental equipment became more and more insufficient.

Short of funds and equipments, the young department was quite hard to operate. As managers of the department, we decided to break through the dilemma with virtual experiment.

\section{The Advantages of Virtual Experiment and Its Development in Chinese Universities}

Virtual experiment can reduce the cost of purchasing and maintaining equipment and thus helps to make up for the shortage of funds. Not limited to laboratory and equipment, students can choose time freely to do virtual experiment. Moreover, virtual experiment can avoid the danger of real experiment. All the advantages above make virtual experiment charming to Chinese teachers and students. 
In recent years, virtual experiments have made great achievements in Chinese universities. L. J. Zou applied virtual experimental technology to the course of Mechanical \& Electrical Transmission Control[1]. Z. W. Dong, R. H. Hu and G. P. Liu build a MCU virtual experiment system with Proteus software and a PLC virtual experiment system with King View software[2]. D. L. Xu, H. Y. Yang and X. L. Liu researched on the application of virtual experiment in Distance Education[3]. J. Wu, Y. M. Sun, W. Lei, et al. Summarizes the construction planning and progress of comprehensive virtual simulation experimental teaching center for mechanical and electronic engineering in Southeast University[4]. G. H. Chou described that students can either simulate robots with RobotStudio or create the simulation platform with Solidworks, UG, etc[5]. Q. X. Li and S. F. Ding developed an Electrical and Hydraulic Control System with FluidSIM-H[6]. J. Zhou and X. Jiang developed a hydraulic course with virtual technology based on Yulong electromechanical control simulation software[7]. W. N. Xu, C. Wang, L. Tang, et al. developed a fully virtual PLC experimental teaching system with GX Developer, MX OPC Server and King View software [8]. The application of virtual reality showed explosive growth in 2016 . Then, 3D virtual experiment became very popular. J. H. Ding, C. Liu, M. Y. Li, et al. designed and builded a 3D virtual reality control simulation system of mechanical and electrical equipment with Unity3D[9]. Y. J. Ye, H. H. Chen, X. D. He, et al. Simulated MIMO random vibration test with Virtual.lab and MATLAB/Simulink [10].

The success of those colleges and universities gives us much inspiration. During our reform, we have used a lot of their experience.

\section{Education Reform with Virtual Experiment}

Virtual Experiments in Courses. In order to overcome the difficulties encountered in development, we have introduced virtual experiments to many courses (as shown in Table 1). Both widely used software (such as Matlab/Simulink, FluidSIM, etc.) and specialized software (such as Virtual Experiment Software for Bolt Group developed by Csjiaxun Company and SmartQuick developed by MinYueTech Company ) are used to carry out virtual experiments.

Table 1 The courses with virtual experiment

\begin{tabular}{|c|c|c|}
\hline Number & Course & Software for virtual experiment \\
\hline 1 & Mechanical Principium & $\begin{array}{l}\text { Virtual Experiment Software for Bolt Group } \\
\text { (Csjiaxun Company) }\end{array}$ \\
\hline 2 & Fundamentals of Control Engineering & Matlab/Simulink \\
\hline 3 & Mechanical Design & Pro/E, Solidworks, Catia, 3D Max, VRML \\
\hline 4 & $\begin{array}{l}\text { Mechanical Electrical Integration } \\
\text { System Design }\end{array}$ & $\begin{array}{l}\text { Matlab/Simulink, Pro/E, Solidworks, Catia, } \\
\text { 3D Max, Unity3D }\end{array}$ \\
\hline 5 & $\begin{array}{l}\text { Hydraulics And Pneumatics Power } \\
\text { Transmission }\end{array}$ & FluidSIM \\
\hline 6 & Introduction to industrial robots & SmartQuick (MinYueTech Company) \\
\hline
\end{tabular}

Virtual experiment has achieved good teaching quality. In 2016, our first graduate's employment rate was over 95\%. Accordingly, Department of Mechanical and Electronic Engineering of Hankou University was popular in recruiting students. Because of remarkable results, we began our graduate education in collaboration with Wuhan University of Science and Technology in 2016.

Training on Developing Virtual Experiment. In addition to experimenting with ready-made software, students are encouraged and trained to develop their own virtual experiments. Students create the experimental environment with the skills of engineering drawing and 3D modeling, design algorithms with mechanical and electronic knowledge, and realized the virtual experiments by programming. That is a good challenge to comprehensively use the knowledge and skills they have learned.

Students' interest is stimulated. Many projects about virtual experiments. have been founded and virtual experiments have been chosen by some students as their graduation design topics. Students' 
innovation ability has been improved significantly. In 2016, the Department of Mechanical and Electronic Engineering have approved 3 innovative training projects for university students in Hubei.

Cooperation with Enterprise. With the explosive growth of the application of virtual reality, companies need a large number of virtual reality talents. At the same time, 3D virtual experiment with virtual reality technology becomes popular and many $3 \mathrm{D}$ virtual experiments remain to be developed. We cooperate with some companies, which have excellent VR techniques, to establish the platform of training VR talents and developing 3D virtual experiments. Then, virtual experiment has become a bridge between university and enterprise.

The cooperation has remarkable achievements. LanOu Technology Co., Ltd. is one of our cooperative partners. On April 20, 2017, LanOu University-enterprise Forum was held in Beijing[11]. Leaders of the Ministry of Education, the National Institute of Educational Administration, more than 150 colleges and universities and industry attended the forum. As one of 23 excellent partners, the Department of Mechanical and Electronic Engineering received Outstanding Achievement Award of University-enterprise Cooperation in the name of Hankou University (as shown in Fig. 1).

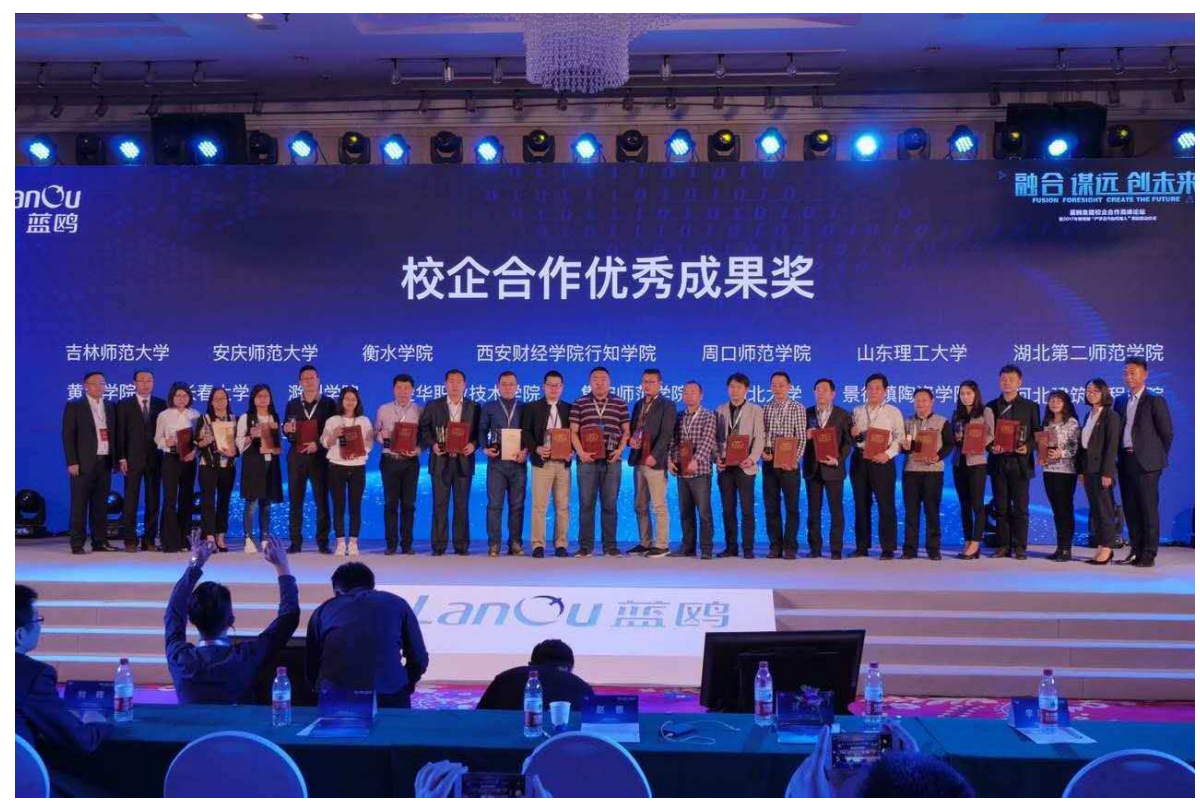

(a) The scene of receiving the trophy and award

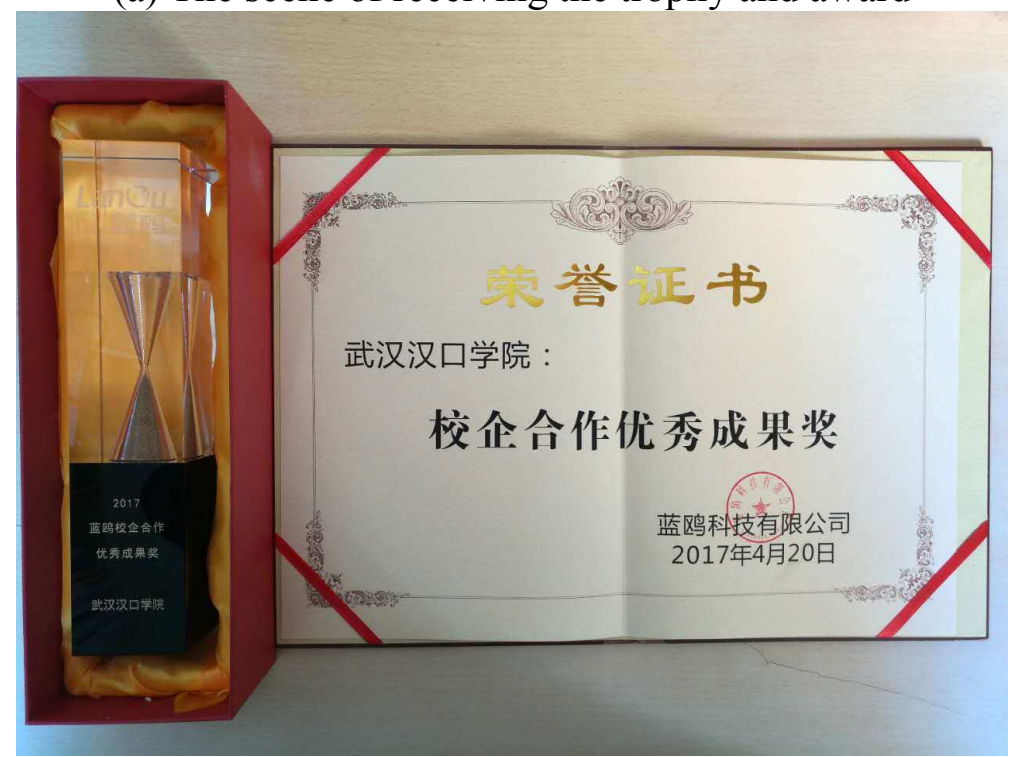

(b) The trophy and award

Figure 1. Outstanding Achievement Award of University-enterprise Cooperation of LanOu Technology Co., Ltd. 
Zhi-ren Technology Co., Ltd is a company of VR technology and is another cooperative partner of the department. They have decided to build a VR center in Hankou University (the design effect is shown as Fig. 2). The center is expected to further enhance the level of our cooperation.

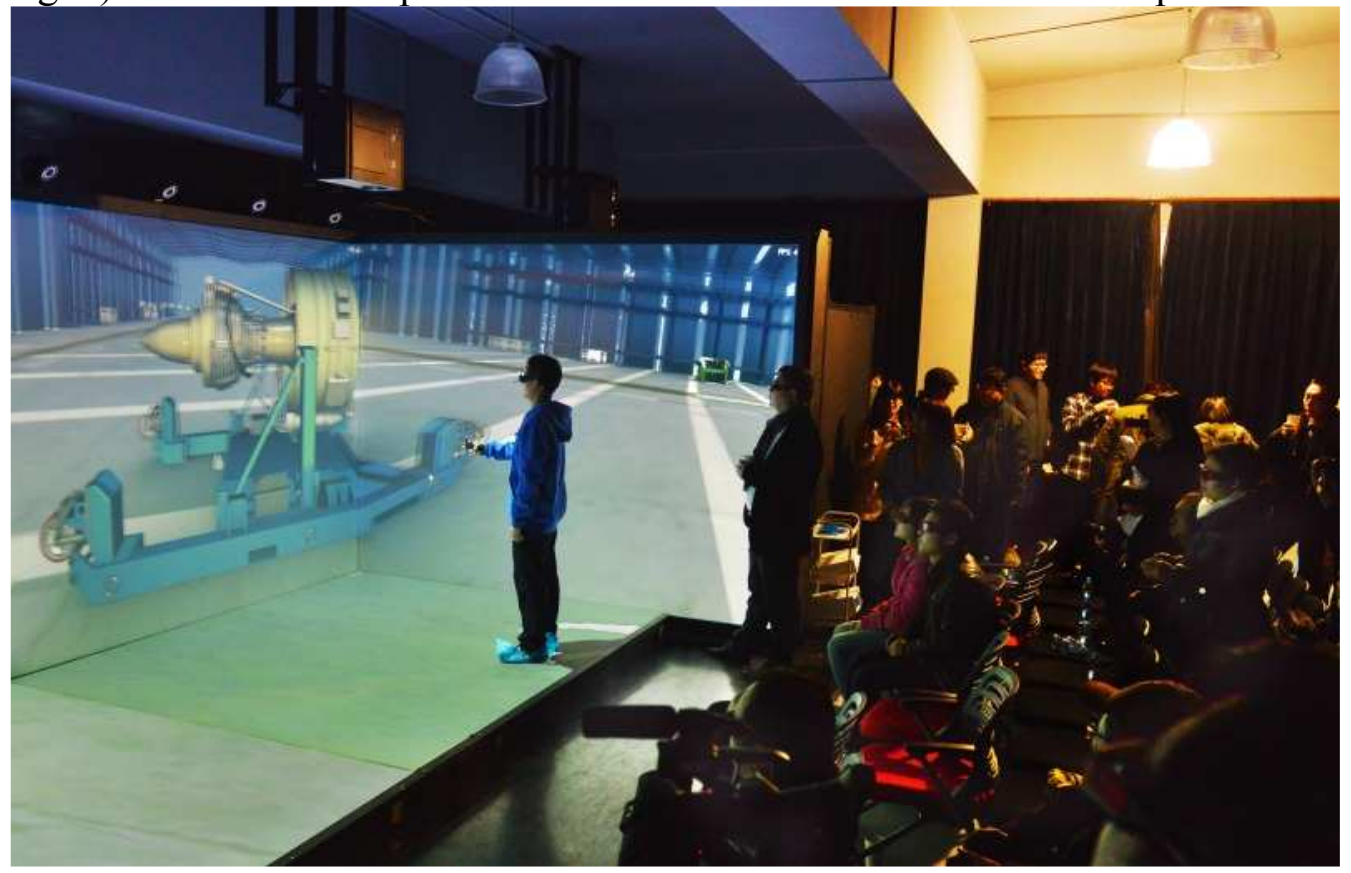

Figure 2. The VR Center of Hankou Universiy \& Zhi-ren Technology Co., Ltd (developing).

\section{Summary}

In the education reform with virtual experiment of the Department of Mechanical and Electronic Engineering of Hankou University, virtual experiment helps to reduce the cost of purchasing and maintaining equipment and improve teaching quality, to train students' innovation ability, and to enhance the cooperation between universities and companies. Virtual experiment is a key factor of the reform, and the mode of its application to university education is feasible.

\section{Acknowledgements}

The research was supported by 2013 pilot project of Comprehensive Reformation in Majors of Undergraduate Universities in Hubei province, China (project No. 80 Department of Mechanical and Electronic Engineering of Hankou University) and Education Research Project of Hankou University (project No. X201310 Research on the application of virtual reality technology in the education of mechanical and electrical engineering).

\section{References}

[1] J. Zou: The Research of Virtual Experimental Technology Using for the Course in Mechanical \& Electrical Transmission Control (MS., Huazhong University of Science \& Technology, China 2009).

[2] Z. W. Dong, R. H. Hu and G. P. Liu: Experimental Technology and Management, Vol.28 (2011) No.8, p.53.

[3] D. L. Xu, H. Y. Yang and X. L. Liu: The Guide of Science \& Education, (2013), No.09, p.134.

[4] J. Wu, Y. M. Sun, W. Lei, et al.: Experimental Technology and Management, Vol.31 (2014) No.10, p.5.

[5] G. H. Chou: New Curriculum Research, (2015) No.11, p.77.

[6] Q. X. Li and S. F. Ding: Chinese Hydraulics \& Pneumatics, (2015) No.9, p.94.

[7] J. Zhou and X. Jiang: Modern Manufacturing Technology and Equipment, (2016) No.08, p.147. 
[8] W. N. Xu, C. Wang, L. Tang, et al.: Research and Exploration in Laboratory, Vol.35 (2016) No.3, p.92.

[9] J. H. Ding, C. Liu, M. Y. Li, et al.: Experimental Technology and Management, Vol.33 (2016) No.9, p.106.

[10] Y. J. Ye, H. H. Chen, X. D. He, et al.: Foreign Electronic Measurement Technology, Vol.35 (2016) No.1, p.39.

[11] Information on http://www.bjcankao.com/html/teach/pxkt/2017/0420/131704.html. 